\title{
Titanium alloy cannulated screws and biodegradable magnesium alloy bionic cannulated screws for treatment of femoral neck fractures: a finite element analysis
}

Kai Ding ${ }^{1 \dagger}$, Weijie Yang ${ }^{1+}$, Jian Zhu ${ }^{2}$, Xiaodong Cheng ${ }^{1}$, Haicheng Wang ${ }^{1}$, Du Hao ${ }^{3}$, Song Yinuo ${ }^{4}$, Yanbin Zhu ${ }^{1}$, Yingze Zhang ${ }^{1,5,6^{*}}$, Wei Chen ${ }^{1,6^{*}}$ and Qi Zhang ${ }^{1 *}$

\begin{abstract}
Background: Cannulated screws (CS) are one of the most widely used treatments for femoral neck fracture, however, associated with high rate of complications. In this study, we designed a new type of cannulated screws called degradable magnesium alloy bionic cannulated screws (DMBCS) and our aim was to compare the biomechanical properties of DMBCS, the traditionally used titanium alloy bionic cannulated screws (TBCS) and titanium alloy cannulated screws (TTCS).

Methods: A proximal femur model was established based on $C T$ data of a lower extremity from a voluntary healthy man. Garden type III femoral neck fracture was constructed and fixed with DMBCS, TBCS, and TTCS, respectively. Biomechanical effect which three type of CS models have on femoral neck fracture was evaluated and compared using von Mises stress distribution and displacement.

Results: In the normal model, the maximum stress value of cortical bone and cancellous bone was 76.18 and 6.82 $\mathrm{MPa}$, and the maximum displacement was $5.52 \mathrm{~mm}$. Under 3 different fracture healing status, the stress peak value of the cortical bone and cancellous bone in the DMBCS fixation model was lower than that in the TTCS and TBCS fixation, while the maximum displacement of DMBCS fixation model was slightly higher than that of TTCS and TBCS fixation models. As the fracture heals, stress peak value of the screws and cortical bone of intact models are decreasing, while stress peak value of cancellous bone is increasing initially and then decreasing.

Conclusions: The DMBCS exhibits the superior biomechanical performance than TTCS and TBCS, whose fixation model is closest to the normal model in stress distribution. DMBCS is expected to reduce the rates of postoperative complications with traditional internal fixation and provide practical guidance for the structural design of CS for clinical applications.
\end{abstract}

\footnotetext{
*Correspondence: dryzzhang@126.com; surgeonchenwei@126.com; drzhangqi1@163.com

${ }^{\dagger}$ Kai Ding and Weijie Yang contributed equally to this work.

'Trauma Emergency Center, Key Laboratory of Biomechanics and Orthopaedic Research Institute of Hebei Province, The Third Hospital of Hebei Medical University, No.139 Ziqiang Road, Shijiazhuang 050051, Hebei, People's Republic of China

Full list of author information is available at the end of the article
}

C C The Author(s). 2021 Open Access This article is licensed under a Creative Commons Attribution 4.0 International License, which permits use, sharing, adaptation, distribution and reproduction in any medium or format, as long as you give appropriate credit to the original author(s) and the source, provide a link to the Creative Commons licence, and indicate if changes were made. The images or other third party material in this article are included in the article's Creative Commons licence, unless indicated otherwise in a credit line to the material. If material is not included in the article's Creative Commons licence and your intended use is not permitted by statutory regulation or exceeds the permitted use, you will need to obtain permission directly from the copyright holder. To view a copy of this licence, visit http://creativecommons.org/licenses/by/4.0/ The Creative Commons Public Domain Dedication waiver (http://creativecommons.org/publicdomain/zero/1.0/) applies to the data made available in this article, unless otherwise stated in a credit line to the data. 
Keywords: Femoral neck fracture, Titanium alloy cannulated screws (TTCS), Titanium alloy bionic cannulated screws (TBCS), Degradable magnesium alloy bionic cannulated screws (DMBCS), Finite element analysis, Stress distribution, Biomechanical test

\section{Introduction}

Femoral neck fracture is a common fracture in the elderly population, accounting for about $60 \%$ of hip fracture [1,2], and is associated with serious medical and social consequences [3-5]. In addition to total hip replacement, osteosynthesis is a well-established operative method for stabilizing femoral neck fracture and currently the most widely used internal fixation instruments were cannulated screws, sliding hip screws, and proximal femoral locking plates [6]. Especially, cannulated screws (CS) was estimated to be used in $78 \%$ of nondisplaced/impacted fractures and $46 \%$ of the displaced fractures due to its minimal operative trauma, lower medical care cost, and socioeconomic burden $[7,8]$. However, the high rate of complications have compromised the operative outcomes, including but not limited to osteonecrosis of the femoral head (14.3-45\%), femoral neck shortening (15.9-30\%), and nonunion (8-19\%) [9-13].

In theory, bone union should include both cortical bone and trabecular bone union, but the role of the latter has been consistently underestimated or even overlooked. Trabecular bone is the center metabolism of bone tissue and also the center of mechanical transmission, bearing $40 \%$ to $70 \%$ of the body load in the proximal femur [14]. In one experimental study, researchers
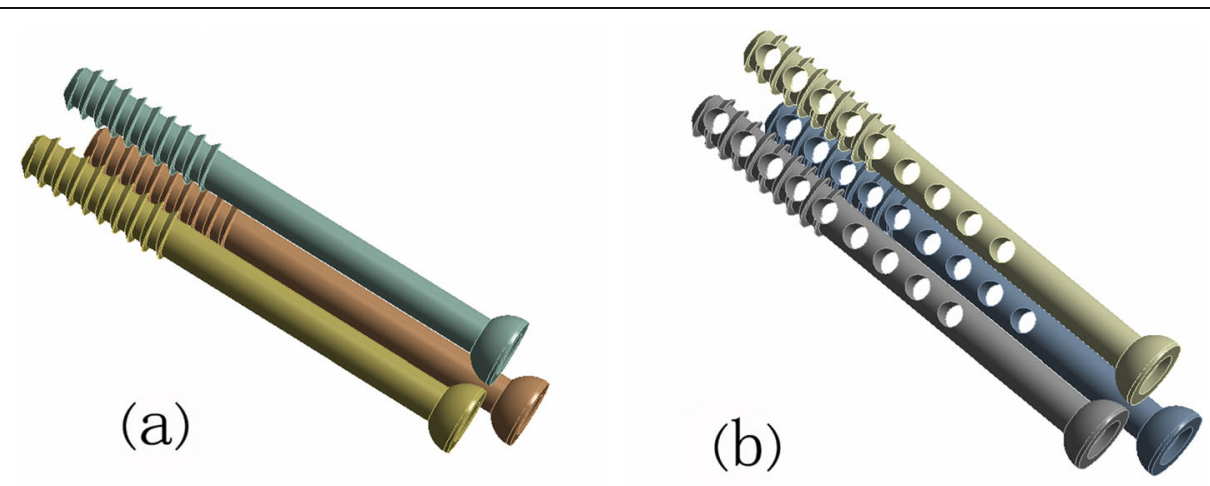

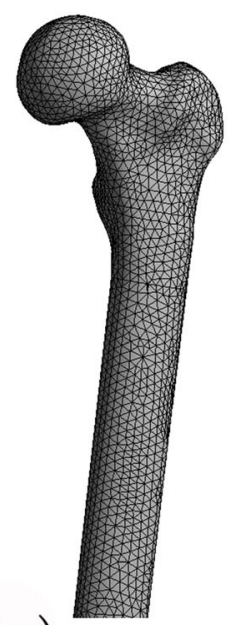

(c)
Fig. 1 The model of TTCS (a), models of DMBCS and TBCS

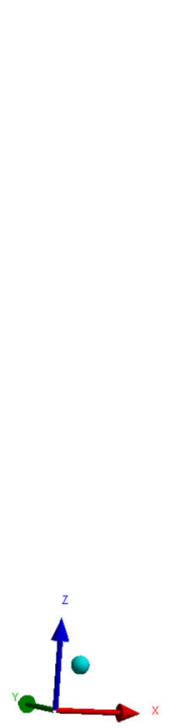

(d)

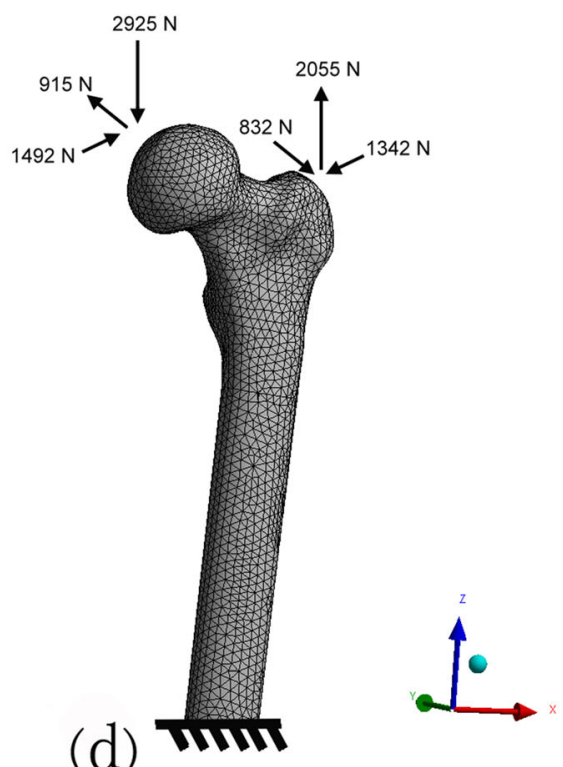

IIIII 


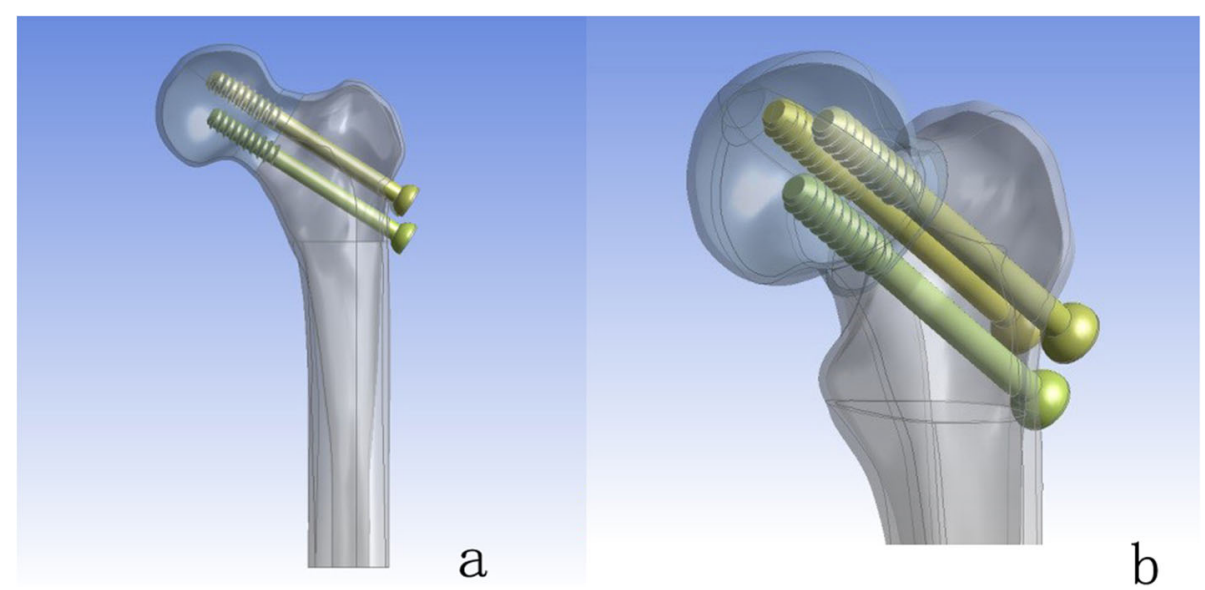

Fig. 2 The model of type Garden III femoral neck fracture was established (a), placement of CS in proximal femur (b)

demonstrated the entire process of bone fracture that $1.5-6.4 \%$ of trabecular bone fracture occurred initially, followed by trabecular bone meshwork fracture and finally the fracture of the cortical bone. Additionally, multiple complications have demonstrated to be related to trabecular bone structure change or suboptimal union, due to decrease of bone mass, premature weightbearing, or internal fixation malposition $[15,16]$. Some scholars also suggested that the difficulty in reconstructing trabecular bone have an important relationship with internal fixation failure [17-19]. Owing to stress shielding and volume occupancy effects, traditional implant blocks the reconstruction of trabecular bone, and the load on the proximal femur cannot be transmitted normally even when the cortical bone fully heals [20].

Given above, our team proposed the concept of bionic fixation and designed the bionic implant with porous structure, which allowed the trabeculae to grow in, known as the bionic implant. It is speculated that reconstruction of the trabeculae with use of such device could improve stress distribution and enhance load conduction. In this study, we use the finite element method to address the biomechanical distinction between this bionic implant and the traditional implants (TBCS and TTCS), with regard to stress distribution and stability.

\section{Methods and properties}

This study has been reviewed and approved by the institutional review board and that it conformed to the provisions of the Declaration of Helsinki. Written informed consent was obtained from the volunteers prior to the study commencement.

\section{Establishing models of proximal femur}

A healthy volunteer (male, 35 years old, height $170 \mathrm{~cm}$, body weight $75 \mathrm{~kg}$ ) without a history of lower extremity injury was scanned by computed tomography scanner (SOMATOM Definition AS Siemens, Germany) with a slicing distance of $0.625 \mathrm{~mm}$ from hip joint to the knee joint. The three-dimensional femur models were established by these images. The geometry and surface were built and sampled by the Geomagic software. The traditional cannulated screw models were constructed based on their real dimension, and 4-mm diameter holes were created on the bionic implant in NX 9.0 (Fig. 1a, b). A model of Garden type III femoral neck fracture was

Table 1 Material properties of all models in this study

\begin{tabular}{llll}
\hline Model & Materials & Young's modulus (GPa) & Poisson's ratio \\
\hline Cortical bone & Cortical bone & 17 & 0.3 \\
Cancellous bone & Cancellous bone & 1.5 & 0.3 \\
TTCS & Ti6Al4V & 110 & 0.316 \\
TBCS & Ti6Al4V & 110 & 0.316 \\
DMBCS & Mg alloy & 45 & 0.316 \\
DMBCS (PO 6 months) & Mg alloy & 36 & 0.316 \\
DMBCS (PO 12 months) & Mg alloy & 9 & 0.316 \\
\hline
\end{tabular}

$\mathrm{PO}$ represents postoperative 

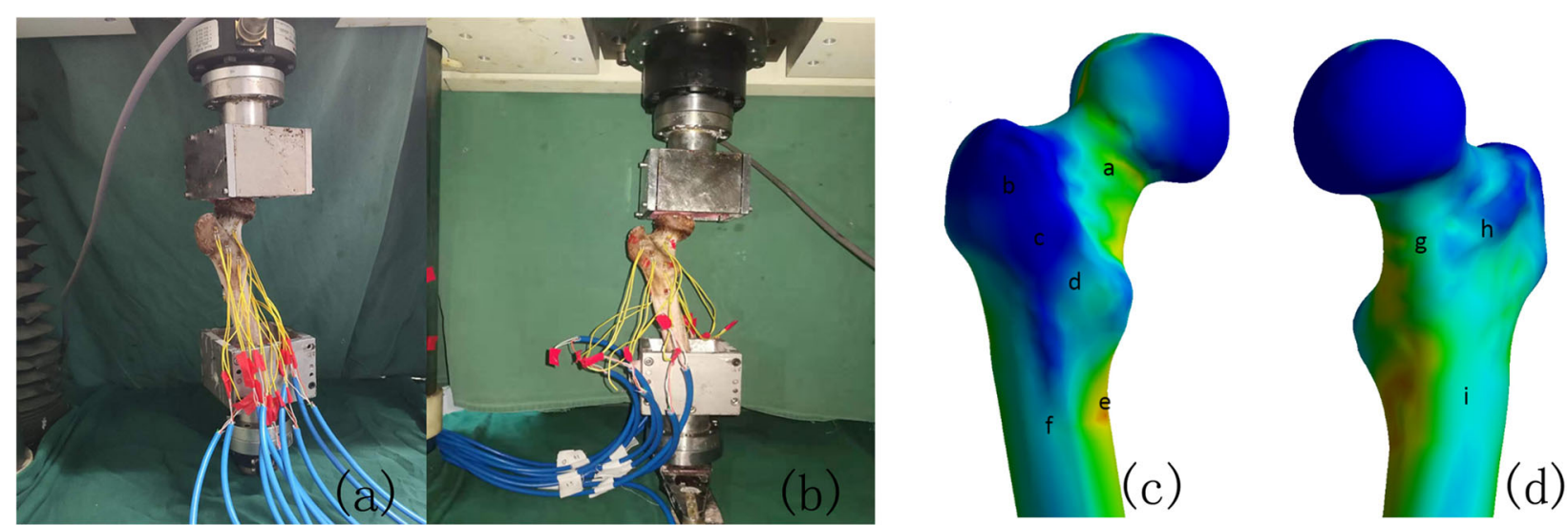

Fig. 3 Comparison between the biomechanical test (a) and finite element analysis (b)

established by NX 9.0 and fixed with traditional and bionic cannulated screws, respectively (Fig. 2).

\section{Material properties and boundary conditions}

The solid models were imported into Hypermesh13.0 for constructing four-node tetrahedral block-structured meshes of bones and screws. Four-node tetrahedral blockstructured meshes of all bones and screws were constructed (Fig. 1c). The models were imported into ABAQUS 6.14. All bone and implant models were assumed to behave with homogeneous, isotropic and linear elastic behavior, and assigned as corresponding material properties according to reported literatures [21] (Table 1).

In assembly models, screw thread and cortical screw were bonding with cancellous bone and cortical bone, respectively. The other bone-implant interfaces were set as contact relationship except for thread/bone and cortical screw/bone. The coefficient of friction was set at 0.3 [22].

As the volunteer's body weight was $75 \mathrm{~kg}$, corresponding to $750 \mathrm{~N}$ of gravity, the loading forces on the femur mimicked the loads at the heel strike of normal walking [23]. Figure 1d shows the head load $(\{x, y, z\}=\{1492$, 915, 2925 $\})$ and abductor force $(\{x, y, z\}=\{1342,832$, $2055\} \mathrm{N})$ (4.54 and 3.45 times body weight, respectively).

\section{Evaluation of stress distribution of proximal femoral cancellous bone}

The finite element analysis model will simulate 3 different bone healing status: non-healed fracture, partly healed fracture and fully healed fracture. Contact condition of non-healed fracture between the fracture surfaces is simulated as non-sliding but separable, to simulate the situation after the fracture has been repositioned and pressurized. The contact condition of partly healed fracture between the fracture surfaces is set to be combined without slippage or separation for cancellous bone. The contact condition of fully healed fracture is set to be combined without slippage or separation. In addition to the displacement, the analysis records von Mises Stress distribution in bone and screws to evaluate the effect of trabecular bone tissue growth into the fixator on the overall stress distribution.

The von Mises stress on the intact proximal femur was tested to analyze the mesh convergence. The convergence criterion used was a change of $<5 \%$. The cortical bone and cancellous bone of final model had 22,137 elements and 40, 237 elements, respectively.

\section{Validation of the finite element models}

In order to verify the finite element models of proximal femur, a specimen of normal proximal femur was selected for biomechanical test (Fig. 3a). The same load condition and boundary conditions were applied. Further, $750 \mathrm{~N}$ load was applied to proximal femur to record strain value of 9 marker points (Fig. 3). The results of comparisons showed that our modelling method is appropriate to be used in the further research, and the difference was not significant (Table 2).

\section{Results}

The von Mises stress distribution and displacement of intact bone

In the normal model, the peak stress values of cortical bone and cancellous bone was $76.18 \mathrm{MPa}$ and $6.82 \mathrm{MPa}$,

Table 2 The strain values of the biomechanical test and finite element analysis $\left(10^{-3}\right)$

\begin{tabular}{|c|c|c|c|c|c|c|c|c|c|}
\hline Maker point & $\mathrm{a}$ & b & c & d & e & $f$ & g & $\mathrm{h}$ & $\mathbf{i}$ \\
\hline Finite element analysis & 4.24 & 0.02 & 0.04 & 1.40 & 6.53 & 2.40 & 5.02 & 2.52 & 2.97 \\
\hline Biomechanical test & 4.43 & 0.02 & 0.04 & 1.53 & 6.82 & 2.75 & 5.27 & 2.45 & 2.67 \\
\hline
\end{tabular}




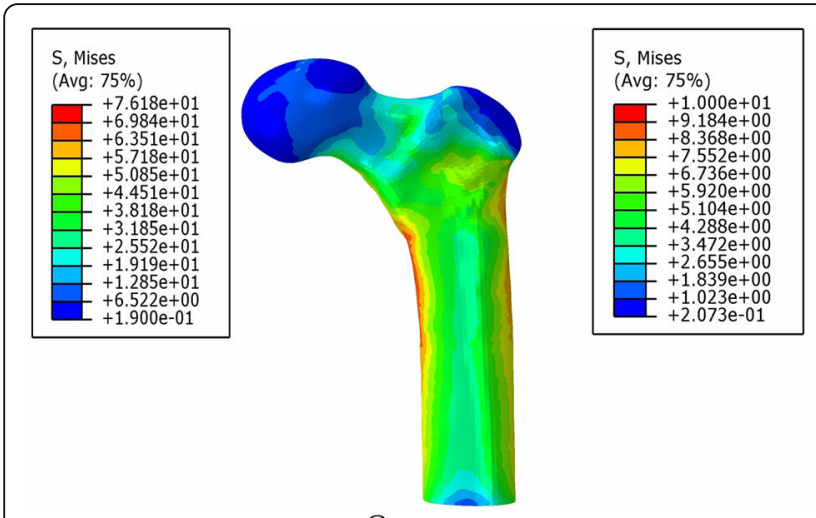

a

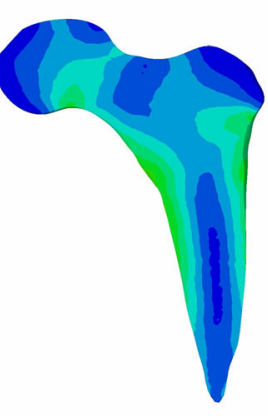

b
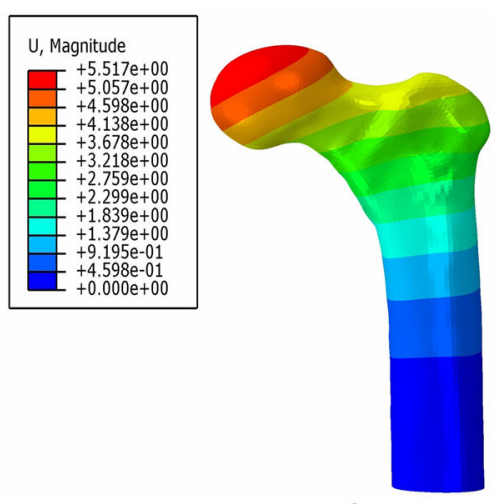

C

Fig. 4 The von Mises stress distribution of cortical bone (a) and cancellous bone (b); the displacement of the intact models (c)

respectively. The maximum displacement was $5.52 \mathrm{~mm}$ (Fig. 4).

The von Mises stress distribution, displacement, and shear stress of different CS fixation models in all three settings

The maximum stress and stress concentration of cortical bone and cancellous bone in the degradable magnesium alloy bionic cannulated screws (DMBCS) fixation model was lower than that in the titanium alloy cannulated screws (TTCS) and titanium alloy bionic cannulated screws (TBCS) fixation models, and the peak bone stress of the three CS fixation models occurred at the holes adjacent to screws. For the screw, the maximum highstress value of the implant was significantly lower than that in the TTCS and TBCS except a non-healed

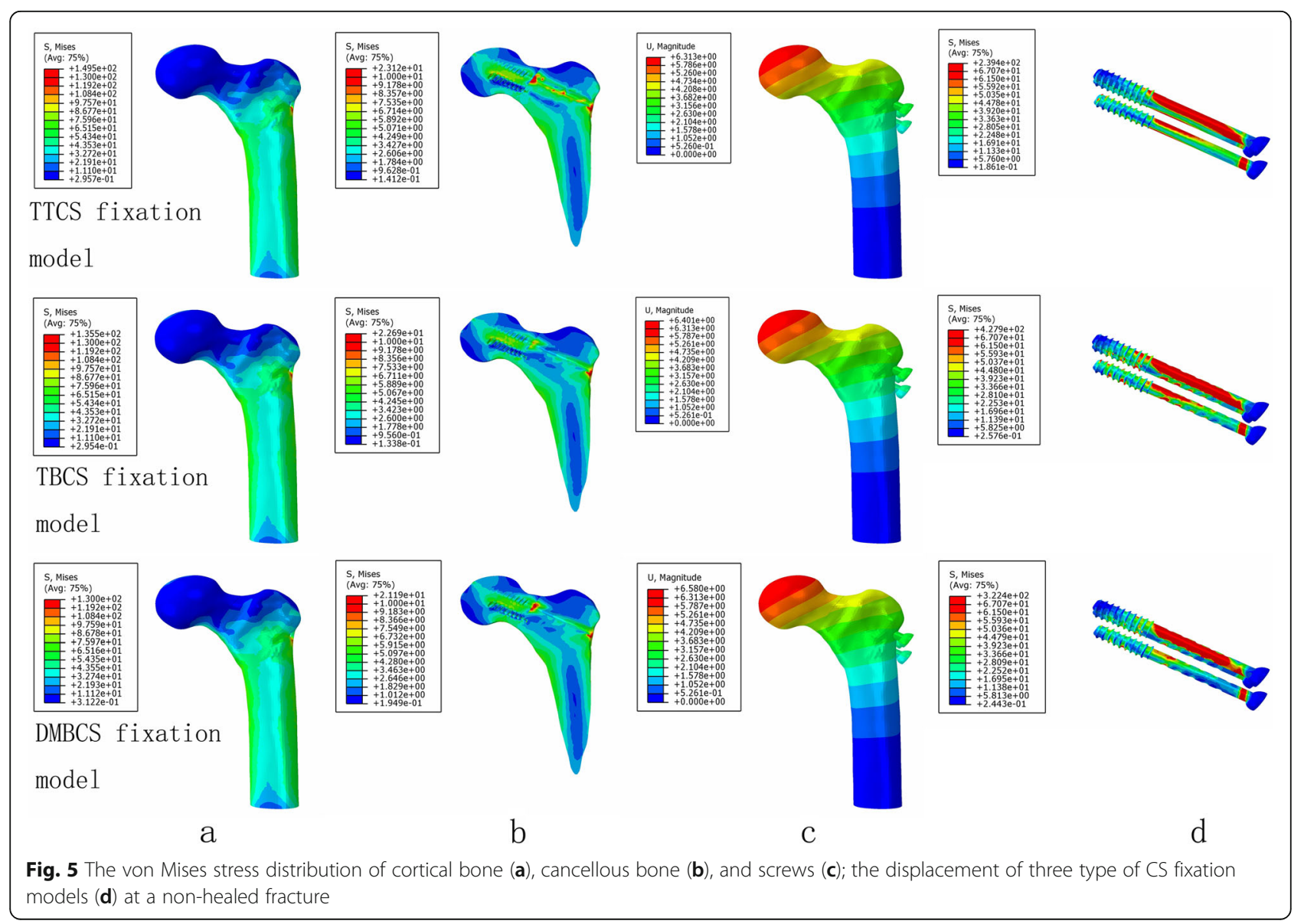




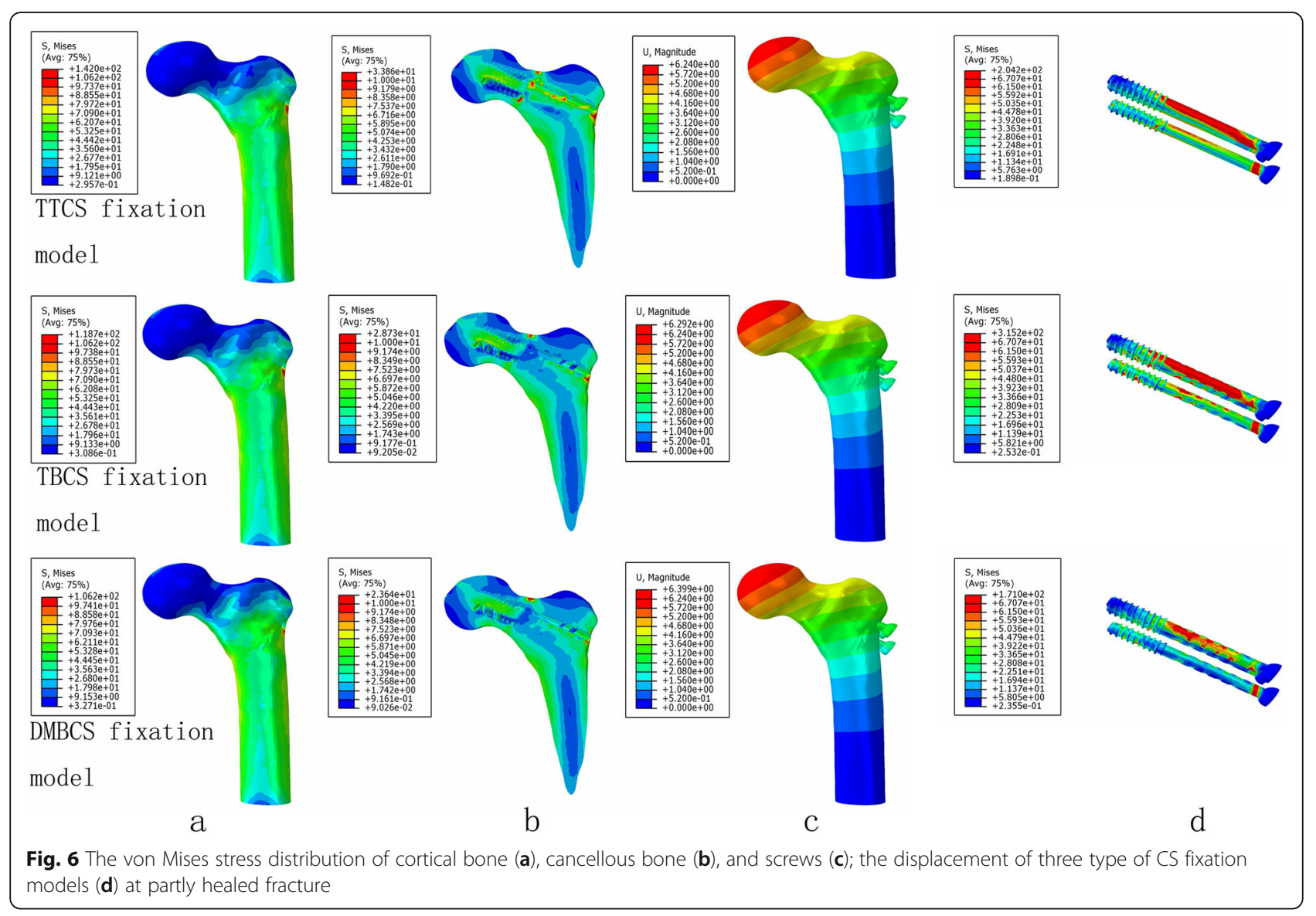

fracture. High-stress value was located at the middle region of screws among three variations under 3 different bone healing status (Figs. 5, 6, and 7) (Table 3).

DMBCS fixation model was higher than TTCS and TBCS fixation in maximum displacement and shear stress. The maximum shear stress of fracture in three implant groups was 16.94 $\mathrm{MPa}, 17.68 \mathrm{MPa}$, and $18.89 \mathrm{MPa}$ at a non-healed fracture (Figs. 5, 6, 7, and 8) (Table 4).

\section{Discussion}

Femoral neck fracture is a common fracture in clinical practice, associated with high post-operative complications. To overcome this problem, we designed the new type of CS. In this experiment, the finite element method was used to analyze the stress distribution and stability of DMBCS, TBCS, and TTCS fixation models. Compared with the TTCS and TBCS, the DMBCS has improved stress distribution of the cortical bone and cancellous bone. The result indicates that DMBCS is expected to provide the theory basis for improving clinical efficacy and biomechanical characters of femoral neck fracture.

According to the results, the maximum stress of cortical and cancellous bones in TTCS is 1.15 and 1.09 times greater than that of DMBCS at a non-healed fracture, and 1.35 and 1.78 times greater than that of DMBCS at fully healed fracture. DMBCS has reduced the maximum stress and stress concentration of cortical and cancellous bone in all three settings. The peak value stress of TTCS is 74\%, 1.19 times and 2.41 times of DMBCS under three healing status. Except for a nonhealed fracture, the stress peak value and stress distribution of DMBCS model are substantially lower than TBCS and TTCS models. DMBCS has improved the stress distribution of fixation models and reduced interference with the surrounding bone.

There are several biomechanical characteristics of DMBCS that explain the biomechanical differences from both traditional and bionic CS. First, the natural elastic modulus of degradable magnesium alloys is low and they are expected to slowly degrade over time. The difference of elastic modulus between cancellous bone and screw is small, and the stress concentration and stress extreme value will also be reduced [23]. This feature is also reflected in the biodegradable internal fixation used for spinal fractures, and the prior study demonstrated the biodegradable material could indeed reduce the stress concentration of the vertebrae during degradation and the stress distribution was closer to the normal model [22]. DMBCS will reduce the disadvantages of stress 


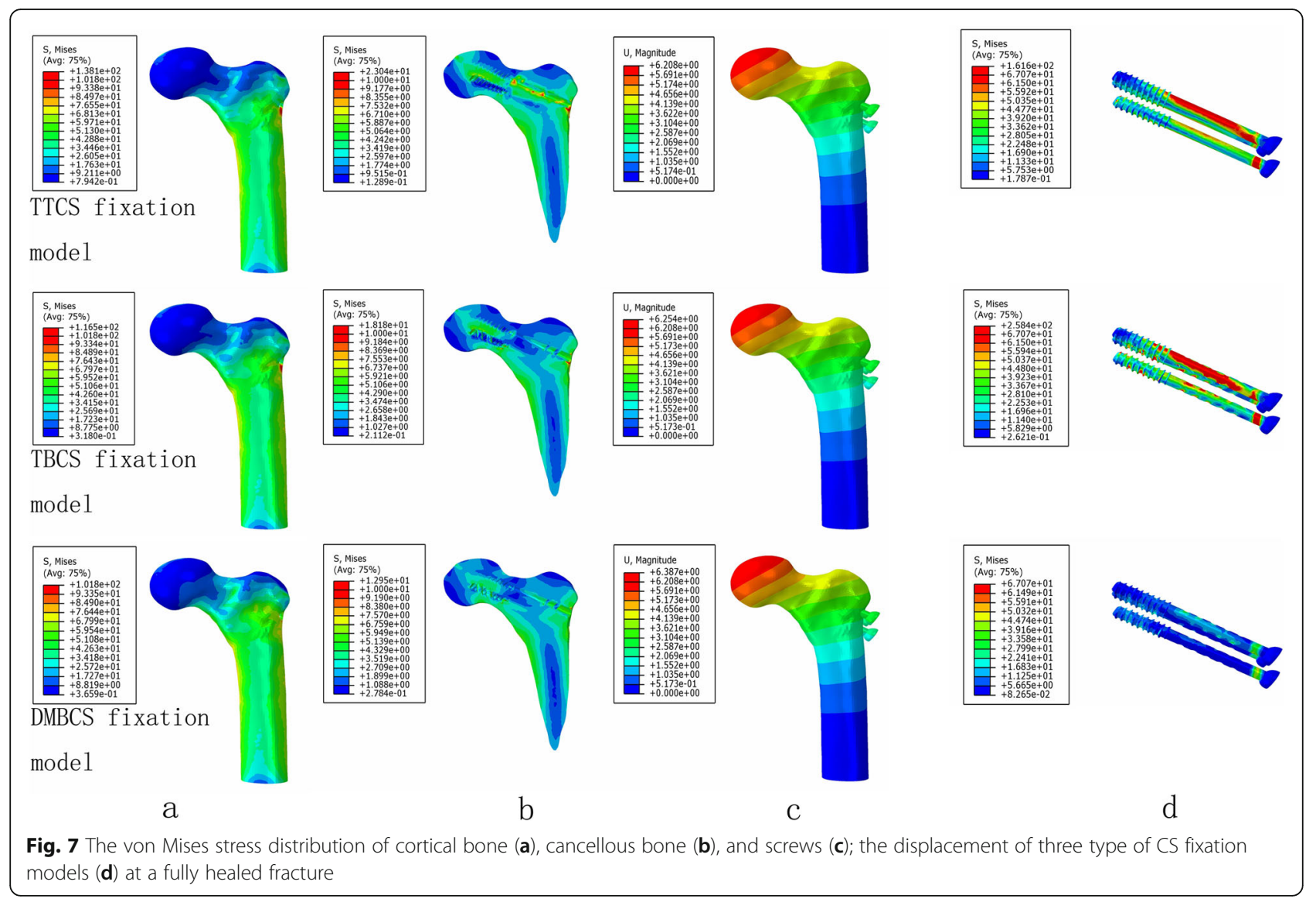

shielding and the risk of relevant complications [24]. Second, the dynamic change of DMBCS conforms to the healing process of femoral neck fracture. DMBCS could provide rigid support for femoral neck fractures, which contributes to the healing process of bone in the early stage. The load carried by the DMBCS will gradually decrease while the load carried by the femoral neck itself will gradually increase, providing an appropriate stress environment for the growth of the trabecular bone [25]. Last but not least, porous structure was consistent with that of trabecular bone in the proximal femur, which can reduce the volumetric mass effect during fracture healing. It can be theoretically speculated that trabecular bone will gradually replace the screws in DMBCS fixation model, thereby avoiding the surgical removal of screws and hence reducing the need for bone grafting procedures [26]. However, the maximum displacement in TTCS fixation model was $96 \%, 98 \%$, and $97 \%$ of that in DMBCS fixation model under three healing status. The maximum displacement and contact/shear stress of DMBCS fixation model is marginally higher than other type of CS models because porous structure and lower modulus of DMBCS reduce stress shielding and volumetric mass effect. We consider that appropriate stress environment and elastic fixation are beneficial to healing process of fracture. Excessively rigid structures may reduce micromotion at the fracture site, such that it is below the threshold required for callus formation [27, 28].

At present, porous metals have been widely used in joint replacement and bone defects, achieving the better results in terms of prognosis and complications, compared with traditional fixation methods [29-31]. Bionic

Table 3 Maximum stress values of screws, cortical bone, and cancellous bone under three healing status (MPa)

\begin{tabular}{|c|c|c|c|c|c|c|c|c|c|}
\hline \multirow[t]{2}{*}{ Healing status } & \multicolumn{3}{|l|}{ TTCS } & \multicolumn{3}{|l|}{ TBCS } & \multicolumn{3}{|l|}{ DMBCS } \\
\hline & Screws & $\begin{array}{l}\text { Cortical } \\
\text { bone }\end{array}$ & $\begin{array}{l}\text { Cancellous } \\
\text { bone }\end{array}$ & Screws & $\begin{array}{l}\text { Cortical } \\
\text { bone }\end{array}$ & $\begin{array}{l}\text { Cancellous } \\
\text { bone }\end{array}$ & Screws & $\begin{array}{l}\text { Cortical } \\
\text { bone }\end{array}$ & $\begin{array}{l}\text { Cancellous } \\
\text { bone }\end{array}$ \\
\hline Non-healed Fracture & 239.42 & 149.54 & 23.12 & 427.90 & 135.50 & 22.69 & 322.40 & 130.00 & 21.19 \\
\hline Partly healed Fracture & 204.23 & 142.04 & 33.86 & 315.16 & 118.68 & 28.73 & 170.97 & 106.23 & 23.64 \\
\hline Fully healed Fracture & 161.61 & 138.10 & 23.04 & 258.41 & 116.50 & 18.18 & 67.07 & 101.80 & 12.95 \\
\hline
\end{tabular}



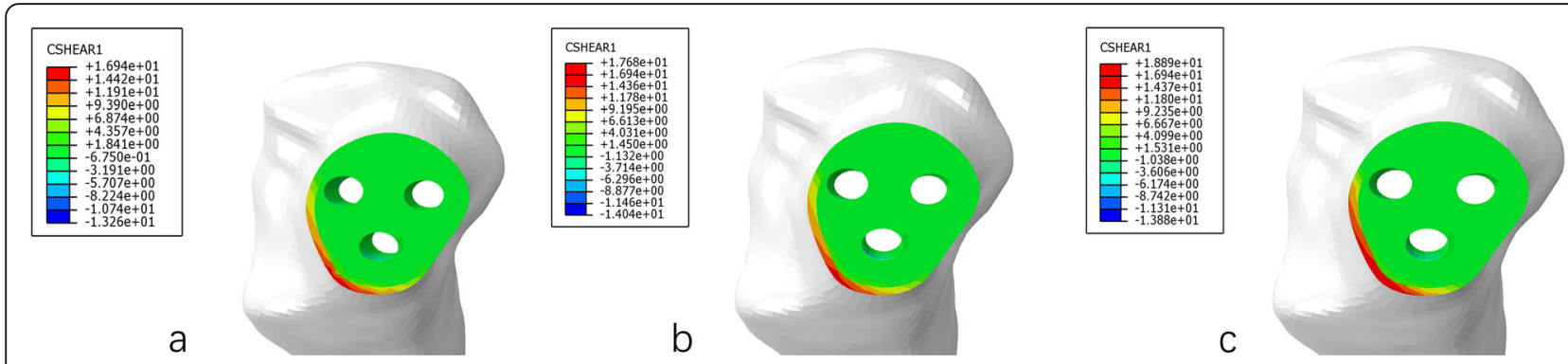

Fig. 8 The shear stress distribution of fracture $\mathbf{a} T T C S, \mathbf{b}$ TBCS, and $\mathbf{c}$ DMBCS

materials including titanium alloy and tantalum metal demonstrated to effectively promote the ingrowth of trabecular bone [32-34]. However, these metal cannot be completely removed in joint replacement and bone defects [35]. Degradable magnesium alloys can overcome the disadvantage. Moreover, the density and elastic modulus of magnesium alloy are close to bone [36]. In addition to the good biomechanical properties, magnesium is also an essential trace element for the human body. Also, the release of magnesium ions during degradation induces the growth of bone [37]. Degradable magnesium alloy screws have been clinically applied in carpal fractures, thumb valgus, and femoral neck fracture, which show good mechanical properties and biosafety [38-40]. Thus, this is our original intention of designing this device that combines magnesium alloys with porous materials.

The design concept of DMBCS was derived from the special structural and mechanical characteristics of the trabecular bone in the proximal femur. The trabecular bone of the femoral neck is adapted to their role in mechanical conduction [14]. Lotz et al. [41] showed that cancellous bone bears $20 \%, 4 \%, 50 \%$, and $70 \%$ of the body load in femoral intertrochanteric, basal, middle, and subcapital regions of the femoral neck, respectively. Therefore, decreasing thickness and number of trabecular bones is one of the most important reasons why elderly patients are prone to femoral neck fractures [42]. Nawathe et al. [19] performed 12 femoral specimens to investigate the injury mechanism of femoral neck fractures caused by lateral fall violence and found only about $1.5-6.4 \%$ of trabecular bone cracked initially. These studies shown the trabecular bone played an important "initiating role" in the development of femoral neck

Table 4 The maximum displacement of three type of CS under three healing status ( $\mathrm{mm}$ )

\begin{tabular}{llll}
\hline Healing Status & TTCS & TBCS & DMBCS \\
\hline Non-healed fracture & 6.31 & 6.40 & 6.58 \\
Partly-healed fracture & 6.24 & 6.29 & 6.40 \\
Fully healed fracture & 6.21 & 6.25 & 6.39 \\
\hline
\end{tabular}

fractures. Therefore, whether the distribution of trabecular bone after surgery can adapt to the change of external environment and whether the reconstruction of trabecular bone is consistent with the transmission direction of human load will directly affect the prognosis of femoral neck fracture treatment. When designing internal fixation in femoral neck fracture, we need to pay attention to the biphasic reconstruction of cancellous bone and cortical bone during the healing process.

Limitations exist in our study. First, this test neglects that the shape and volume of DMBCS will change during degradation, which may affect the results. Second, the material properties of the cortical bone and cancellous were assumed to be isotropic, linearly elastic, and homogeneous behavior, whereas bones are really composed of anisotropic viscoelastic material.

In summary, DMBCS fixation model is closest to the normal model in the stress distribution, and exhibited better biomechanical performance than the other traditional implants. DMBCS can meet the requirements of dynamic fixation of femoral neck fractures, and reduce the interference on cortical and cancellous bone. DMBCS is a promising internal fixation device for femoral neck fracture.

\section{Abbreviations}

CS: Cannulated screws; TTCS: Titanium alloy cannulated screws; TBCS: Titanium alloy bionic cannulated screws; DMBCS: Degradable magnesium alloy bionic cannulated screws

\section{Acknowledgements}

I would like to thank all authors for help and support in the process of data analysis and article writing.

\section{Authors' contributions}

QZ, WC, and YZ designed the study. QZ, WC, HD, and YZ searched relevant studies. KD, WY, JZ, HW, XC, and YS analyzed and interpreted the data. KD wrote the manuscript. WC, $Y Z$, and QZ contributed most in the revision of this manuscript. All authors approved the final version of the manuscript.

\section{Funding}

This study was supported by the Support Program for the National Natural Science Foundation of China (Grant No. 82072447, 81401789), the Hebei National Science Foundation-Outstanding Youth Foundation (Grant No. H2017206104). The funding source has no role in study design, conduction, data collection or statistical analysis. 


\section{Availability of data and materials}

Please contact author for data requests.

\section{Declarations}

\section{Ethics approval and consent to participate}

This study was approved by the ethics committee of the Third Hospital of Hebei Medical University. Informed consent was obtained from all the participants.

\section{Consent for publication}

Written informed consent was obtained from volunteers to authorize the publication of their data.

\section{Competing interests}

The authors declare that they have no competing interests.

\section{Author details}

'Trauma Emergency Center, Key Laboratory of Biomechanics and Orthopaedic Research Institute of Hebei Province, The Third Hospital of Hebei Medical University, No.139 Ziqiang Road, Shijiazhuang 050051, Hebei, People's Republic of China. ${ }^{2}$ School of Medicine, Nankai University, Tianjin 300071, People's Republic of China. ${ }^{3}$ The First Affiliated Hospital, and College of Clinical Medicine of Henan University of Science and Technology, Luoyang 471003, China. ${ }^{4}$ Yanjing Medical College, Capital Medical University, Beijing, China. ${ }^{5}$ Chinese Academy of Engineering, Beijing 100088, People's Republic of China. ${ }^{6} \mathrm{NHC}$ Key Laboratory of Intelligent Orthopeadic Equipment (The Third Hospital of Hebei Medical University), Shijiazhuang, China.

Received: 5 July 2021 Accepted: 11 August 2021 Published online: 18 August 2021

\section{References}

1. Chen W, Lv H, Liu S, Liu B, Zhu Y, Chen X, et al. National incidence of traumatic fractures in China: a retrospective survey of 512187 individuals. Lancet Glob Health. 2017;5(8):e807-17. https://doi.org/10.1016/S2214-109X(1 7)30222-X

2. Major $L$, North JB. Predictors of mortality in patients with femoral neck fracture. J Orthop Surg (Hong Kong). 2016;24(2):150-2.

3. Braithwaite RS, Col NF, Wong JB. Estimating hip fracture morbidity, mortality and costs. J Am Geriatr Soc. 2003;51(3):364-70. https://doi.org/10.1046/j.1 532-5415.2003.51110x

4. Abrahamsen B, van Staa T, Ariely R, Olson M, Cooper C. Excess mortality following hip fracture: a systematic epidemiological review. Osteoporos Int 2009;20(10):1633-50. https://doi.org/10.1007/s00198-009-0920-3.

5. Klop C, Welsing PM, Cooper C, Harvey NC, Elders PJ, Bijlsma JW, et al. Mortality in British hip fracture patients, 2000-2010: a population-based retrospective cohort study. Bone. 2014;66:171-7. https://doi.org/10.1016/j. bone.2014.06.011

6. Florschutz AV, Langford JR, Haidukewych GJ, Koval KJ. Femoral neck fractures: current management. J Orthop Trauma. 2015;29(3):121-9. https:// doi.org/10.1097/BOT.0000000000000291

7. Crist BD, Eastman J, Lee MA, Ferguson TA, Finkemeier CG. Femoral neck fractures in young patients. Instr Course Lect. 2018;67:37-49.

8. Slobogean GP, Spraque SA, Scott T, McKee M, Bhandari M. Management of young femoral neck fractures: is there a consensus? Injury. 2015;46(3):43540. https://doi.org/10.1016/j.injury.2014.11.028.

9. Chen C, Yu L, Tang X, Liu MZ, Sun LZ, Liu C, et al. Dynamic hip system blade versus cannulated compression screw for the treatment of femoral neck fractures: a retrospective study. Acta Orthop Traumatol Turc. 2017; 51(5):381-7. https://doi.org/10.1016/j.aott.2017.07.006.

10. Lu-Yao GL, Keller RB, Littenberg B, Wennberg JE. Outcomes after displaced fractures of the femoral neck. A meta-analysis of one hundred and six published reports. J Bone Joint Surg Am. 1994;76(1):15-25. https://doi.org/1 0.2106/00004623-199401000-00003

11. Zlowodzki M, Ayeni O, Petrisor BA, Bhandari M. Femoral neck shortening after fracture fixation with multiple cancellous screws: incidence and effect on function. J Trauma. 2008:64(1):163-9. https://doi.org/10.1097/01.ta. 0000241143.71274 .63 .
12. Slobogean GP, Sprague SA, Scott T, Bhandari M. Complications following young femoral neck fractures. Injury. 2015:46(3):484-91. https://doi.org/10.1 016/j.injury.2014.10.010.

13. Li M, Cole PA. Anatomical considerations in adult femoral neck fractures: how anatomy influences the treatment issues? Injury. 2015;46(3):453-8. https://doi.org/10.1016/j.injury.2014.11.017.

14. Nawathe S, Nguyen BP, Barzanian N, Akhlaghpour H, Bouxsein ML, Keaveny TM. Cortical and trabecular load sharing in the human femoral neck. J Biomech. 2015;48(5):816-22. https://doi.org/10.1016/j.jbiomech.2014.12.022.

15. Song HK, Choi HJ, Yang KH. Risk factors of avascular necrosis of the femoral head and fixation failure in patients with valgus angulated femoral neck fractures over the age of 50 years. Injury. 2016;47(12):2743-8. https://doi. org/10.1016/j.injury.2016.10.022.

16. Sen RK, Tripathy SK, Goyal T, Aggarwal S, Tahasildar N, Singh D, et al. Osteosynthesis of femoral-neck nonunion with angle blade plate and autogenous fibular graft. Int Orthop. 2012;36(4):827-32. https://doi.org/10.1 007/s00264-011-1344-1.

17. Keaveny TM, Yeh OC. Architecture and trabecular bone-toward an improved understanding of the biomechanical effects of age, sex and osteoporosis. J Musculoskelet Neuronal Interact. 2002;2(3):205-8.

18. Zhang Q, Chen W, Liu HJ, Li ZY, Song ZH, Pan JS, et al. The role of the calcar femorale in stress distribution in the proximal femur. Orthop Surg. 2009;1(4):311-6. https://doi.org/10.1111/j.1757-7861.2009.00053.x.

19. Nawathe S, Akhlaghpour H, Bouxsein ML, Keaveny TM. Microstructural failure mechanisms in the human proximal femur for sideways fall loading. J Bone Miner Res. 2014;29(2):507-15. https://doi.org/10.1002/jbmr.2033.

20. Güven M, Yavuz U, Kadioğlu B, Akman B, Kilinçoğlu V, Unay K, et al. Importance of screw position in intertrochanteric femoral fractures treated by dynamic hip screw. Orthop Traumatol Surg Res. 2010;96(1):21-7. https:// doi.org/10.1016/j.otsr.2009.10.008

21. Sowmianarayanan S, Chandrasekaran A, Kumar RK. Finite element analysis of a subtrochanteric fractured femur with dynamic hip screw, dynamic condylar screw, and proximal femur nail implants--a comparative study. Proc Inst Mech Eng H. 2008;222(1):117-27. https://doi.org/10.1243/0954411 9JEIM156

22. Tsuang FY, Hsieh YY, Kuo YJ, Chen $\mathrm{CH}_{\text {, Lin }} \mathrm{FH}_{1}$ Chen $\mathrm{CS}$, et al. Assessment of the suitability of biodegradable rods for use in posterior lumbar fusion: an in-vitro biomechanical evaluation and finite element analysis. PLoS One. 2017;12(11):e0188034. https://doi.org/10.1371/journal.pone.0188034

23. Taheri NS, Blicblau AS, Singh M. Comparative study of two materials for dynamic hip screw during fall and gait loading: titanium alloy and stainless steel. J Orthop Sci. 2011;16(6):805-13. https://doi.org/10.1007/s00776-0110145-0.

24. Brown TD, Pedersen DR, Baker KJ, Brand RA. Mechanical consequences of core drilling and bone-grafting on osteonecrosis of the femoral head. J Bone Joint Surg Am. 1993;75(9):1358-67. https://doi.org/10.2106/00004623-1 99309000-00011.

25. Lambers FM, Koch K, Kuhn G, Ruffoni D, Weigt C, Schulte FA, et al. Trabecular bone adapts to long-term cyclic loading by increasing stiffness and normalization of dynamic morphometric rates. Bone. 2013;55(2):325-34. https://doi.org/10.1016/j.bone.2013.04.016.

26. Kiani F, Wen C, Li Y. Prospects and strategies for magnesium alloys as biodegradable implants from crystalline to bulk metallic glasses and composites-a review. Acta Biomater. 2020;103:1-23. https://doi.org/10.101 6/j.actbio.2019.12.023.

27. Gardner MJ, Nork SE, Huber P, Krieg JC. Less rigid stable fracture fixation in osteoporotic bone using locked plates with near cortical slots. Injury. 2010; 41(6):652-6. https://doi.org/10.1016/j.injury.2010.02.022.

28. Kenwright J, Richardson JB, Goodship AE, Evans M, Kelly DJ, Spriggins AJ, et al. Effect of controlled axial micromovement on healing of tibial fractures. Lancet. 1986;2(8517):1185-7. https://doi.org/10.1016/s0140-6736(86)92196-3.

29. Styron JF, Marinello PG, Peers S, Seitz WH Jr. Survivorship of Trabecular Metal Anchored Glenoid Total Shoulder Arthroplasties. Tech Hand Up Extrem Surg. 2016;20(3):113-6. https://doi.org/10.1097/BTH. 0000000000000127.

30. Henricson A, Linder L, Nilsson KG. A trabecular metal tibial component in total knee replacement in patients younger than 60 years: a two-year radiostereophotogrammetric analysis. J Bone Joint Surg Br. 2008;90(12): 1585-93.

31. Niemeläinen M, Skyttä ET, Remes V, Mäkelä K, Eskelinen A. Total knee arthroplasty with an uncemented trabecular metal tibial component: a 
registry-based analysis. J Arthroplasty. 2014;29(1):57-60. https://doi.org/10.1 016/j.arth.2013.04.014.

32. Malizos KN, Bargiotas K, Papatheodorou L, Hantes M, Karachalios T. Survivorship of monoblock trabecular metal cups in primary THA : midterm results. Clin Orthop Relat Res. 2008;466(1):159-66. https://doi.org/10.1007/ s11999-007-0008-3.

33. Stiehl JB. Trabecular metal in hip reconstructive surgery. Orthopedics. 2005; 28(7):662-70. https://doi.org/10.3928/0147-7447-20050701-13.

34. Biemond JE, Aquarius R, Verdonschot N, Buma P. Frictional and bone ingrowth properties of engineered surface topographies produced by electron beam technology. Arch Orthop Trauma Surg. 2011;131(5):711-8. https://doi.org/10.1007/s00402-010-1218-9.

35. Bobyn JD, Stackpool GJ, Hacking SA, Tanzer M, Krygier JJ. Characteristics of bone ingrowth and interface mechanics of a new porous tantalum biomaterial. J Bone Joint Surg Br. 1999;81(5):907-14. https://doi.org/10.1302/ 0301-620X.81B5.0810907.

36. Kamrani S, Fleck C. Biodegradable magnesium alloys as temporary orthopaedic implants: a review. Biometals. 2019;32(2):185-93. https://doi. org/10.1007/s10534-019-00170-y.

37. Yu X, Zhao D, Huang S, Wang B, Zhang X, Wang W, et al. Biodegradable magnesium screws and vascularized iliac grafting for displaced femoral neck fracture in young adults. BMC Musculoskelet Disord. 2015;16(1):329. https://doi.org/10.1186/s12891-015-0790-0.

38. Windhagen H, Radtke K, Weizbauer A, Diekmann J, Noll Y, Kreimeyer U, et al. Biodegradable magnesium-based screw clinically equivalent to titanium screw in hallux valgus surgery: short term results of the first prospective, randomized, controlled clinical pilot study. Biomed Eng Online. 2013;12(1):62. https://doi.org/10.1186/1475-925X-12-62

39. Zhao D, Huang S, Lu F, Wang B, Yang L, Qin L, et al. Vascularized bone grafting fixed by biodegradable magnesium screw for treating osteonecrosis of the femoral head. Biomaterials. 2016;81:84-92. https://doi. org/10.1016/j.biomaterials.2015.11.038.

40. Lee JW, Han HS, Han KJ, Park J, Jeon H, Ok MR, et al. Long-term clinical study and multiscale analysis of in vivo biodegradation mechanism of $\mathrm{Mg}$ alloy. Proc Natl Acad Sci U S A. 2016;113(3):716-21. https://doi.org/10.1073/ pnas. 1518238113.

41. Lotz JC, Cheal EJ, Hayes WC. Stress distributions within the proximal femur during gait and falls: implications for osteoporotic fracture. Osteoporos Int. 1995;5(4):252-61. https://doi.org/10.1007/BF01774015.

42. Rachner TD, Khosla S, Hofbauer LC. Osteoporosis: now and the future. Lancet. 2011;377(9773):1276-87. https://doi.org/10.1016/S0140-6736(10)6234 9-5.

\section{Publisher's Note}

Springer Nature remains neutral with regard to jurisdictional claims in published maps and institutional affiliations.

Ready to submit your research? Choose BMC and benefit from:

- fast, convenient online submission

- thorough peer review by experienced researchers in your field

- rapid publication on acceptance

- support for research data, including large and complex data types

- gold Open Access which fosters wider collaboration and increased citations

- maximum visibility for your research: over $100 \mathrm{M}$ website views per year

At $\mathrm{BMC}$, research is always in progress.

Learn more biomedcentral.com/submissions 